\title{
JUSTICIA RESTAURATIVA Y MEDIACIÓN PENAL
}

\author{
Autor: Julián Carlos Ríos Martín ${ }^{1}$ \\ Profesor Propio Agregado de Derecho Penal \\ Universidad Pontificia Comillas
}

\section{Resumen}

Este artículo pretende ofrecer una reflexión sobre los postulados de la justicia restaurativa, como paradigma innovador en el ámbito de la justicia penal. Se abordan cuestiones actuales de relevancia jurídico-penal, se exponen sus principios y se explican las posibilidades que los procesos restaurativos otorgan a personas infractoras, víctimas y la propia comunidad para la resolución pacífica y creativa de conflictos de índole penal.

Palabras clave: justicia restaurativa; mediación; reparación; víctimas; derecho penal; diálogo.

\section{Restorative justice and mediation}

\footnotetext{
${ }_{1}^{1}$ jrios@comillas.edu
} 


\begin{abstract}
This article offers a reflection on the principles of restorative justice as a innovative paradigm in the field of criminal justice. It addresses current issues relevant in the field of penal law. We talk about the principles and they are also explained the possibilities that offenders, victims and community members have to get the penal conflict resolved by peaceful and creative means. In order to complement the analysis, a real case of crime resolved in mediation, is offered.
\end{abstract}

Key words: restorative justice; mediation; reparation; victims; penal law; dialogue.

Recibido: 21/04/2016

Aceptado: 08/06/2016

\title{
1. INTRODUCCIÓN
}

La mediación como instrumento de diálogo al servicio de la pacificación y resolución de todo tipo de conflictos (familiares, sociales, políticos e incluso internacionales) está cobrando un importante protagonismo. También, más recientemente, en los sistemas penal y penitenciario de nuestro país. Dos leyes se han encargado de incorporarla a nuestro ordenamiento jurídico. Por un lado, la LO 1/2015 de modificación del Código Penal establece que "El juez o tribunal también podrá condicionar la suspensión de la ejecución de la pena al cumplimiento de alguna o algunas de las siguientes prestaciones o medidas: 1 . El cumplimiento del acuerdo alcanzado por las partes en virtud de mediación" (art. 84.1 CP). Por otro, la LO 4/2105 sobre el estatuto de la víctima recoge la regulación de la práctica de los servicios de mediación y el acceso de la víctima a los mismos.

A nuestro juicio, "una buena teoría es condición de posibilidad de una buena praxis". Por ello, el horizonte desde el que hay que contemplar la mediación penal es el de la justicia restaurativa. Ésta supone una concepción fuerte, abierta y positiva del ser humano, de la sociedad, así como "otra" idea de justicia de contornos claramente perfilables por oposición a la justicia retributiva y que van siendo traducidos en documentos y prácticas de los organismos especializados de la Organización de Naciones Unidas ${ }^{2}$. Digamos ya que, a falta de una definición universalmente válida, entendemos por justicia restaurativa, en sentido amplio, el método de resolver los conflictos que atiende prioritariamente a la protección

\footnotetext{
${ }^{2}$ Vid. Pascual Rodríguez, E., "La mediación en el Derecho penal de adultos en la fase de enjuiciamiento", Estudios de Derecho Judicial, (núm. 111, 2006), pp. 107-138.
} 
de la víctima y al restablecimiento de la paz social, mediante el diálogo comunitario y el encuentro personal entre los directamente afectados, con el objeto de satisfacer de modo efectivo las necesidades puestas de manifiesto por los mismos, devolviéndoles una parte significativa de la disponibilidad sobre el proceso y sus eventuales soluciones, procurando la responsabilización del infractor y la reparación de las heridas personales y sociales provocadas por el delito3.

Sin duda la mediación penal no es la "panacea" universal para la solución de los conflictos penales -tampoco la justicia retributiva- pero sí algo más que una novedosa "tercera vía" o un mero complemento de la justicia vigente.

El sistema penal convencional, si bien es imprescindible para el mantenimiento del orden social, en cierta manera no respeta ni atiende convenientemente las necesidades personales (físicas, emocionales) de las víctimas. Supone, en la mayoría de los casos, una experiencia escasamente reparadora para ellas e intensamente dolorosa (nada responsabilizadora) para los infractores ${ }^{4}$. Bien puede decirse que, desposeídas las partes del conflicto, son instrumentalizadas con fines punitivos, orientando toda la formalización procedimental hacia pretensiones procesales ajenas por completo a la solución que unos y otros podrían haber considerado como razonable; se orienta únicamente a la imposición de una pena. Efectivamente esta opción es la que se corresponde con las posiciones que afirman que "no le corresponde al Derecho Penal restañar las heridas morales causadas por el delito y resolver el conflicto humano desencadenado por éste"

La justicia restaurativa se ha tratado de legitimar señalando que sirve para la consecución de los fines de la pena. Se trata de la utilización por parte del Derecho penal de un nuevo instrumento — la conciliación/reparación— que no es una sanción, pero que permite la consecución de los fines que persigue. El problema de este discurso es que en él se insiste tanto en acentuar las posibilidades preventivo-generales de la justicia restauradora, que se olvida de subrayar su propio contenido y características, en cuanto representa una forma de solución de conflictos que complementa al sistema punitivo, pero desde otras premisas: frente a la confrontación y a la imposición autoritaria, se apuesta por el diálogo; su fin principal no es el castigo sino la reparación y la pacificación; y, en vez de excluir socialmente, busca la integración y la reinserción. Estas notas, lejos de

\footnotetext{
${ }^{3}$ United Nations, Handbook on restorative justice programmes, Criminal Justice Handbook Series New York: United Nations - Office on Drugs and Crime, New York, 2006.

${ }^{4}$ Como señala Braithwaite, la mediación es un proceso donde todas las personas con algún interés afectado por una injusticia tiene la oportunidad de discutir las consecuencias de la misma y lo que habría que hacerse para poner las cosas en su lugar. El valor clave es que, dado que la injusticia daña, la justicia debe sanar, (Braithwaite, J., "The fundamentals of restorative" en Dinen, S., Jowit, A. y Newton, T. (eds.), A Kind of Mending: Restorative Justice in the Pacific Islands, Australian National University Press, Camberra, 2010, pp. 35-43).

${ }^{5}$ Silva Sánchez, J., "Sobre la relevancia jurídico-penal de la realización de actos de "reparación", Revista del Poder Judicial, (núm. 45, 1997).
} 
ser características accidentales del instrumento propuesto, definirían su esencia y han de ser tenidas en cuenta para la explicación de la justicia restaurativa como modelo de respuesta penal.

Frente a sus innumerables ventajas, no podemos dejar de apuntar ciertos riesgos: la mediación puede quedar anclada en un carácter instrumental y reducida a una mera formalidad burocrática en la que primen criterios pragmáticos; tampoco puede ser concebida por los poderes públicos como medio de solucionar las dilaciones y retrasos en la administración de justicia; obviamente la víctima no puede utilizarla como instrumento para negociar más ventajosamente la indemnización a la que eventualmente crea tener derecho; y, por el infractor, no puede ser utilizada para obtener, sin grandes costes ni contrapartidas, una rebaja de la pena. Para evitar tales riesgos, la mediación y su aplicación tienen que estar en una permanente revisión crítica.

\section{CLAVES DE LA JUSTICIA RESTAURATIVA}

\subsection{Una opción por el diálogo}

La justicia restaurativa, a través de la mediación, trata de encontrar soluciones que impulsen a quienes están implicados a escucharse en vez de usar la fuerza, explorar arreglos en lugar de dar órdenes, buscar soluciones que fomenten la compensación y no represalias, de modo que se "anime a los hombres a hacer el bien

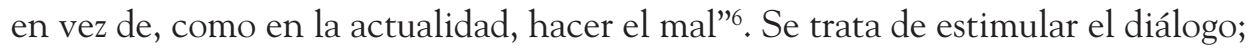
ayudar a ponerse en el lugar del otro; cultivar actitudes empáticas; cuidar los procesos de responsabilización personal (único antídoto efectivo frente a la reincidencia); evitar la frecuente confusión entre la responsabilidad ética ${ }^{7}$ (que mira hacia el pasado pero, sobre todo, hacia el futuro) y la responsabilización criminal (proceso de adquisición de conocimiento que mira siempre hacia el pasado y, en último extremo, permite que los protagonistas puedan ver reafirmada su presencia en el marco de la intervención institucional ante su conflicto) ${ }^{8}$.

Si bien a primera vista puede parecer utópico pretender que víctima y autor se sienten a dialogar, esta posibilidad resulta mucho más verosímil cuando se averigua que la mediación dispone de técnicas y criterios de intervención que hacen

${ }^{6}$ Christie, N., Los límites del dolor, Fondo de Cultura Económica, México 1984.

${ }^{7}$ Jonas, H., El principio de responsabilidad, Herder, Barcelona, 1995.

${ }^{8}$ Como señala Pranis, la justicia restaurativa asume que los humanos somos profundamente relacionales. Hay una necesidad humana fundamental que significa estar en buena relación con los demás. El enfoque restaurativo reconoce y trabaja con esta necesidad humana, Pranis, K., "Restorative values" en Johnstone, F. y Van Ness, D. W. (eds.), Handbook of restorative justice, Willan Publishing, Nueva York, 2007, pp. 59-74. 
viable lo que pudiera parecer una utopía. Si la palabra es un atributo de los seres humanos y el diálogo es lo que nos convierte en seres relacionales e interdependientes, su utilización no puede ser neutra en la justicia penal para el logro de los fines que pretende.

\subsection{Una apuesta por la verdad}

El reconocimiento voluntario de la autoría ${ }^{9}$ y el acto de responsabilidad que en él se manifiesta obtenido tras un proceso de mediación) es el punto de partida para la resolución eficaz del conflicto. No sólo es una pretensión procesal y premisa mayor para la aplicación de de una pena. El derecho a la verdad forma parte de la reparación debida. Solamente desde la verdad se puede reparar adecuadamente, se superan los miedos y se pacifica la convivencia de manera duradera; sólo desde la verdad se individualiza justa y útilmente la respuesta penal. Se trata de hacer frente al reto moral más imponente al que convocara Kant con su "atrévete a saber"; tener la audacia de conocer la verdad material y no sólo la procesalmente relevante, de ahondar en las consecuencias materiales y morales de todo proceso penal, de lo que ello supone para las personas y sus circunstancias más allá de lo que pueda constar en los autos y expedientes judiciales. Se trata de reconocer la constatación zubiriana de que "el hombre es un ente que no puede desentenderse de la verdad, sino que ésta constituye un ingrediente esencial de su propia realidad humana"10.

\subsection{Una apuesta por el reconocimiento de la víctima}

La justicia restaurativa nos introduce de lleno en el tiempo de las víctimas. Definitivamente no puede disimularse que todo el sistema penal moderno se edificó en torno a la idea de castigar al culpable, olvidando la protección de los intereses y derechos de la víctima. Con Roxin se puede afirmar que "nuestra justicia penal es, sobre todo, un sistema para hacer fracasar los intereses de la víctima, aunque sería racional, desde el punto de vista político social, comenzar, en el intento de una solución del conflicto social emergente del hecho punible, por colocar a la víctima en situación de indemnidad y, recién después, ver si existe algo más que disponer" certero diagnóstico de Hassemer. El daño se despersonaliza y lo injusto de lo su-

\footnotetext{
${ }^{9}$ Que, naturalmente, no implica necesariamente acuerdo sobre todos los hechos conforme son literalmente expuestos y relatados en el acta de acusación.

${ }^{10}$ Nicolás Marín, J. A., "La teoría zubiriana de la verdad" en Nicolás Marín, J. A. y Barroso Fernández, O. (cols.), Balance y perspectivas de la filosofía de X. Zubiri, Comares, Granada 2004, pp. 129-147.

${ }^{11}$ Roxin, C., "La reparación en el sistema de los fines de la pena" en Maier, B. J. (comp.) De los delitos y de las víctimas, Ad-hoc, Buenos Aires, 1992, p. 140.
} 
cedido se configura como un atentado contra valores considerados en abstracto, condiciones básicas para nuestra vida social, desapareciendo la visión del delito como suceso interpersonal que, además de afectar a la sociedad, ha producido un daño tangible que conviene reparar.

A pesar de previos esfuerzos de algunos prestigiosos juristas y criminólogos, la victimología en nuestro país se ha hecho visible tardíamente y parcialmente, sólo respecto de determinadas categorías de víctimas, las provocadas por el terrorismo y más tarde las que padecen la violencia de género. No obstante tal limitación inicial, el respeto que las víctimas de todo delito merecen ha terminado por situarse en el primer plano de atención de los expertos. En todo caso, es conveniente alertar acerca del riesgo de que su recién adquirida relevancia en el proceso penal sirva de coartada para, utilitaria y torticeramente, recortar los derechos del infractor y las garantías del sistema o incrementar la dureza de su respuesta. Víctima e infractor están situados en posiciones procesales diferentes. Sin embargo, el único momento de enfrentamiento irresoluble entre ambos lo constituye el infeliz momento del delito. Es entonces cuando sus intereses son radicalmente contrapuestos. Lo que más tarde debe procurar el proceso penal contemplado desde la mirada restaurativa es superar la confrontación y apostar por el diálogo. Para ello, habrá de asegurar la protección inmediata y efectiva de la víctima y su derecho a la reparación del daño, y hacer posible que el infractor asuma los hechos - de haber sido responsable de los mismos- y repare el daño causado $^{12}$.

La justicia restaurativa, al reconocer a la víctima, al devolverle el protagonismo que merece y velar por la cobertura de sus necesidades, presenta un enorme potencial sanador para restañar sus heridas, ampliando al mismo tiempo las funciones asignadas al sistema de justicia penal mediante la inclusión de la reparación del daño en todas sus modalidades (patrimonial, simbólica, emocional), lo que constituye, como señala Rojas Marcos ${ }^{13}$, la mejor forma de superar "la obsesión crónica con los malvados que quebrantaron sus vidas y que les impide cerrar la herida y pasar página. Pues es un hecho que los perjudicados por sucesos traumáticos que tienen el pasaporte de víctima temporal se recuperan mejor que aquellos que, consciente o inconscientemente, se aferran a esta nacionalidad por un tiempo ilimitado". Se trata, en suma, de ayudar a vivir incluso los delitos más graves como una "terrible odisea, pero una odisea ya superada".

En este sentido, el Estatuto de la víctima reconoce el derecho de toda víctima, desde el primer contacto con las autoridades y funcionarios, incluyendo el

\footnotetext{
${ }^{12}$ Los procesos restaurativos llamados Conferencias, reconocidas por las Naciones Unidas, promueven la participación de la víctima, de la red de apoyo de esta, de la persona ofensora y su red de apoyo, así como de miembros familiares y otros significativos para los participantes, incluidos aquellos que pertenecen a la comunidad cercana afectada por la ofensa.

${ }^{13}$ Rojas Marcos, L., “¿Condenados a víctimas perpetuas?”, El País, (28 de julio de 2005).
} 
momento previo a la presentación de la denuncia, a recibir información sobre los servicios de justicia restaurativa disponibles, en los casos en que sea legalmente posible (art. 5.1 LO 4/2015). El acceso de las víctimas a los servicios de justicia restaurativa, se hará en los términos que reglamentariamente se determine, con la finalidad de obtener una adecuada reparación material y moral de los perjuicios derivados del delito, cuando se cumplan los siguientes requisitos:

a) El infractor haya reconocido los hechos esenciales de los que deriva su responsabilidad;

b) la víctima haya prestado su consentimiento, después de haber recibido información exhaustiva e imparcial sobre su contenido, sus posibles resultados y los procedimientos existentes para hacer efectivo su cumplimiento;

c) el infractor haya prestado su consentimiento;

d) el procedimiento de mediación no entrañe un riesgo para la seguridad de la víctima, ni exista el peligro de que su desarrollo pueda causar nuevos perjuicios materiales o morales para la víctima;

e) no esté prohibida por la Ley para el delito cometido (art. 15 LO 4/2105).

\subsection{Una apuesta por la responsabilización del infractor}

Ser responsable implica aceptar que -ante la estructura jurídico-formal de reproche- se ha de responder y se han de asumir las consecuencias de los actos, así como tratar de reparar sus efectos dañinos. Ello equivale a poner en juego la dimensión ética del ser humano y convertir a cada persona en reconductora de su propia vida. Contra lo que suele pensarse, una buena parte de las personas están dispuestas a disculparse y reparar el daño causado. Ese es también el máximo interés de algunas víctimas, mucho más atentas a esos objetivos que al castigo como tal. Sin embargo, el sistema de justicia retributiva no incentiva ni el reconocimiento de la autoría del delito ni su perdón; más bien estimula lo contrario. Al poner el acento en la responsabilidad criminal, minimiza la responsabilidad ética. Así, por paradójico que parezca, el sistema penal convencional termina generando irresponsabilización, despersonalización, incapacidad para asumir consecuencias. Todo un impagable servicio a la reincidencia.

Desde la mirada de la justicia restaurativa se contempla un sujeto libre (aunque condicionado por las circunstancias), capaz de dialogar y de adoptar decisiones morales y, sobre todo, perfectible, porque aunque nuestros comportamientos nos pertenecen, no nos definen y, menos aún, nos pre-determinan o configuran definitivamente nuestra identidad.

En esta línea, también contribuye a sostener el postulado de la reinserción social como horizonte último del sistema penal y, singularmente, como orientación del sistema punitivo y penitenciario. La reinserción social de los infractores 
no es un mero y vano deseo alumbrado por los primeros ilustrados, retomado por el humanismo cristiano y los correccionalistas y asumido por todas las corrientes humanizadoras del Derecho penal. El referente de la reinserción -en muchos casos, sería más apropiado hablar de inserción- se asienta, como hemos ya indicado, en la perfectibilidad humana, en la innata capacidad de los seres humanos no sólo de modificar el entorno que habitan sino de transformarse y perfeccionarse a sí mismos. Sin ella, no habría aprendizaje posible; la enseñanza, la transmisión de la experiencia, serían tareas inútiles.

En definitiva, la justicia restaurativa, al tiempo que responsabiliza al infractor frente a la víctima y le compromete con la efectiva reparación del daño causado, atiende a sus necesidades reales ${ }^{14}$, especialmente la de conocer la trascendencia y alcance del mal causado por medio, precisamente, de la persona que lo ha sufrido; posibilita su rehabilitación y su reinserción en la sociedad y facilita el análisis de la etiología del delito para atender sus déficits personales y sociales, si los hubiere.

\subsection{Una apuesta por el mantenimiento de la naturaleza pública del sistema penal}

La mediación aquí contemplada no provoca la privatización del proceso porque no concibe el conflicto como un "asunto privado". No se propone como sistema alternativo sino como una herramienta de que se vale la justicia penal para una más adecuada respuesta al delito, integrada en el sistema penal e incorporada a las diferentes fases del procedimiento.

El carácter público de este instrumento de justicia restaurativa queda garantizado en tanto que corresponde a los diversos poderes y órganos estatales -desde el legislador hasta los operadores jurídicos- definir y delimitar el marco de la mediación, sus límites objetivos, subjetivos, formales y estructurales, y asegurar la observancia de las garantías procesales, evitando o corrigiendo los eventuales abusos que pudieran aparecer. La acción pública continúa en manos del Ministerio Fiscal, que debe mantenerla y fijar los límites penológicos que no deben ser sobrepasados en el acuerdo de mediación, correspondiendo al juez determinar en la resolución que ponga fin al procedimiento la consecuencia jurídica de la infracción penal, así como los contenidos reparadores. Con independencia de la función fiscalizadora y garantista del Ministerio público y del juez al controlar y sancionar los contenidos, así como el alcance de los acuerdos de reparación suscritos por las partes, se trata desde luego de un modelo de justicia innovador porque se construye en "horizontal", por medio del diálogo entre iguales, sin fórmulas encorsetadas

\footnotetext{
${ }^{14}$ Sánchez Alvárez, P., "Mediación penal comunitaria: desde dónde y hacia dónde”, Estudios de Derecho Judicial, (núm. 11, 2006), pp. 25 y ss.
} 
ni imposiciones, frente a la "verticalidad" y rigidez formal del proceso penal convencional ${ }^{15}$. Pero la introducción en el sistema de justicia penal de estructuras y perspectivas novedosas no altera su esencia ni autoriza a vincular la llamada "privatización" del derecho penal con la mediación.

Desde otro punto de vista, se argumenta asimismo con la privatización a que inevitablemente aboca la mediación a partir de la constatación de que la mayor presencia y protección de la víctima en el proceso penal se encuentra frecuentemente asociada al intento de otorgarle un mayor espacio al resarcimiento del daño ocasionado por el delito, atendida la naturaleza privada de la reparación. En suma, se plantea, especialmente en círculos científicos, la "ubicación de la reparación en el sistema de la teoría de la pena” reflejándose así el temor de que a fuerza de atender prioritariamente los intereses de la víctima se termine "por suprimir la pretensión penal o su necesidad de realización" y finalmente se diluya la diferencia ontológica entre el derecho civil y el derecho penal. Sin embargo, no hay que olvidar que la participación en una mediación en el seno de un procedimiento penal, por el rasgo esencial de voluntariedad a la que nos referiremos, no se resuelve forzosamente en la consecución de un acuerdo, y de ser así, la reparación consensuada -que puede no tener contenido indemnizatorio e incluso ser de carácter simbólico- coexiste en todo caso con la sanción penal. Así pues, la reparación pactada en el eventual acuerdo no sustituye a la penal, la atenúa en su imposición, o la sustituye o suspende en su ejecución. Tampoco desde esta perspectiva los temores acerca de la influencia de la mediación penal sobre la disolución de los límites públicos y privados del ordenamiento jurídico se hallan, pues, justificados.

La presencia cada día más intensa y extensa de la llamada Justicia penal negociada, que en nuestro ordenamiento jurídico penal se concreta en los llamados "juicios de conformidad", esa "suerte de negocio jurídico procesal" ${ }^{16}$, y su injustificada vinculación con la mediación, abonan la confusión -a menudo interesada- y conducen a trasplantar a la mediación las sospechas que se propagan en torno a la justicia penal negociada de contribuir a contaminar el derecho penal -paradigma del derecho público- con elementos propios del derecho privado.

\section{LA MEDIACIÓN PENAL Y LAS GARANTÍAS PROCESALES}

Para alcanzar un incremento en la legitimidad del sistema penal y obtener una mayor satisfacción de los ciudadanos en la resolución de sus conflictos de esta

${ }^{15}$ Martínez Escamilla, M., "Justicia reparadora, mediación y sistema penal. Diferentes estrategias, ¿los mismos objetivos?", en Estudios Penales en Homenaje a Enrique Gimbernat, Edisofer, Madrid, 2008.

${ }^{16}$ Oliva Santos, A., "Presunción de inocencia, prueba de cargo y sentencia de conformidad", http:// www.ucem.es/info/procesal/revista/inocencia.html. 
naturaleza -atendiendo a las necesidades de la víctima y apoyando la posibilidad de reinserción de los infractores-, la mediación se revela como un instrumento privilegiado en el seno del proceso penal. Para ello ha de ser respetuoso con todas las garantías procesales, reconocerlas como el logro más perfilado del Derecho penal, sustantivo y procesal. Por ello, la apuesta realista de la justicia restaurativa estará siempre presidida por garantizar eficazmente la presunción de inocencia, el derecho a la defensa, el derecho a la tutela efectiva de los tribunales, en la convicción de que su reubicación en un horizonte más amplio de justicia evitará su reducción a meras declaraciones formales y retóricas.

Una primera exigencia: las personas que intervienen deben decidir libremente su participación ${ }^{17}$. Desde el fundamento de la mediación como instrumento de transformación personal y relacional se puede afirmar que, únicamente, si existe libertad puede aparecer en el infractor la responsabilización de su conducta y, en la víctima, la posibilidad de elaboración emocional de la situación traumática sufrida. La devaluación de la voluntariedad en la participación es uno de los riesgos de la mediación. Ni la víctima, ni el acusado, pueden verse obligados a iniciar una mediación, o a mantenerse en ella, o a adoptar acuerdos que les sean perjudiciales para sus intereses. A estos efectos, el mediador debe informar a las partes de los derechos, obligaciones y consecuencias de su participación, así como de su libertad para iniciar o abandonar el proceso en cualquier momento, sin que ello tenga consecuencias jurídicas. Esta información tiene que transmitirse de forma amplia, detallada y comprensible, explicando los pasos que el proceso penal va a seguir si existe mediación y, también, en caso contrario.

Por otro lado, la libertad de participación guarda relación directa con las garantías procesales. Ni la víctima, ni la persona acusada, pueden sufrir consecuencias jurídicas restrictivas de derechos por el inicio o abandono del proceso de mediación. En este sentido, los siguientes postulados pueden ser reveladores de la importancia de este asunto:

a) La decisión de participar en una mediación puede ser un indicio de intervención en el hecho delictivo susceptible, en principio, de valoración judicial, pero no debe tener consecuencias jurídicas. Éste es uno de los riesgos más importantes y que merece una reflexión, pues puede afectar directamente al derecho a la presunción de inocencia. Cuando desde la oficina judicial se ofrezca a la persona acusada la posibilidad de participar en una mediación, no puede realizarse únicamente en función del reconocimiento de hechos, sino en función de la naturaleza y circunstancias del hecho criminal, de la intensidad de los indicios que estén acreditados y de la posibilidad

\footnotetext{
${ }^{17}$ Seguimos, en lo que sigue de este apartado, el texto Sáez C., La Mediación Penal y Penitenciaria. Un programa para su regulación, Thompson-Aranzadi, Pamplona, 2008, pp. 319 y ss.
} 
de reparación. No obstante, cuando comienza una mediación, aparece un reconocimiento implícito de los hechos por parte del acusado que, en principio, podría influir en la valoración probatoria que en su momento realice el juez sentenciador. Este hecho no tendría trascendencia si la mediación finalizase y el acusado se mantuviese en el reconocimiento de los hechos objeto de denuncia; pero sí puede tenerla si decide, una vez iniciado, abandonar el proceso mediador. Esta presunción inicial no tiene por qué ser determinante, pues una persona acusada puede comenzar la mediación y luego abandonarla, si lo que realmente ha ocurrido, y por lo que decide su participación, no es susceptible de traducción jurídica en una infracción penal, o no está conforme con los hechos que la víctima expresa. Ahora bien, una vez que se firma un acta de reparación, se está infiriendo un reconocimiento de hechos; a partir de este momento, si el acusado decide abandonar la mediación ya finalizada, la confidencialidad del mediador deja de tener carácter absoluto pues el documento -acta de reparación-que se remite al juzgado y al fiscal aporta información de la que inevitablemente se deduce cierta participación en los hechos. Siendo esto así, el juez no puede basar la motivación de una eventual sentencia condenatoria en esta circunstancia, como tampoco lo puede hacer con ninguna prueba obtenida ilícitamente, o en los trámites ordinarios del proceso penal cuando el abogado entra a la sala de vistas a negociar con el fiscal acerca de una posible conformidad que luego no se da en la práctica. Por tanto, ni la apertura voluntaria, ni el cierre del proceso de mediación son elementos que puedan ser tomados en consideración dentro de la valoración probatoria. Sería conveniente que la ley reguladora de la mediación determinase la imposibilidad de tal valoración. A pesar de ello, el imputado tiene que adoptar la decisión de participar en una mediación con toda la información y siendo consciente de las posibles repercusiones jurídicas, aunque es deseable que estas sean nulas. Por ello, sería importante que si el ofrecimiento de la mediación se hiciera en el momento de información a la persona detenida de sus derechos-arts. 118 y 520 LECr- se hiciese hincapié en la naturaleza, fines y consecuencias de su decisión, en todos sus extremos. Esta información debe volver a reiterarse una vez iniciada la mediación antes de la firma del documento de consentimiento informado.

b) Se debe evitar una utilización genérica de la mediación que pueda ser instrumentalizada, sin valoración de sus aspectos fundamentales, en orden a descargar de trabajo a los operadores jurídicos de las instituciones penales. Este hecho conlleva un grave riesgo en orden a la libertad y al reconocimiento del derecho a un juicio justo. Hemos asistido a una situación similar con la implantación y desarrollo de la institución de la conformidad procesal. Con ella, el abogado y el acusado pueden conformarse con los hechos y la pena que solicita el Ministerio Fiscal y así, el juez, dictar una sentencia de confor- 
midad. Si se realiza por los trámites del juicio rápido esta conformidad puede traducirse en una rebaja de la pena en un $1 / 3$; si se efectúa por los trámites del procedimiento abreviado no tiene tal rebaja explícita, pero se activa otra que puede suponer una perversión de esta institución. La práctica habitual es que el Ministerio Fiscal en el escrito de calificación provisional sobrecargue la pena para potenciar la conformidad y ofrecer, así, una sensible rebaja. Ante esta situación no son infrecuentes las situaciones en las que el acusado se ve, no de derecho, pero sí de hecho, sutilmente condicionado ante una eventual aplicación más severa del reproche penal -más pena- a aceptar la conformidad, limitándose de esta forma el derecho a un juicio justo. Por otro lado, se ha llegado a situaciones jurídicamente inadmisibles como la influencia en la determinación de la pena de la decisión de no participar en la conformidad procesal. El Tribunal Constitucional se ha manifestado sobre esta situación en relación con la vulneración del derecho a la tutela judicial efectiva -art. 24.1 CE- y con el derecho a no declararse culpable -art. 24.2 CE-. En la STS 75/2007, de 16 de abril, se declara la nulidad de la sentencia en la que se optó por no rebajar la pena solicitada por el Ministerio Fiscal con el siguiente argumento: "si hubieran reconocido los hechos, o al menos no hubieran negado los más evidentes, y no hubieran obligado a hacer un juicio larguísimo se justificaría el que se les tratara con más magnanimidad". Por tanto, no se puede basar la pena impuesta en el ejercicio de los derechos fundamentales a no declarar contra sí mismo y a no confesarse culpable.

La situación descrita puede ocurrir con la puesta en práctica de la mediación. No se debe crear una situación en la que el infractor se pueda sentir sutilmente obligado a participar en una mediación si percibe que su negativa se puede traducir en una situación más perjudicial que si continúa por el trámite ordinario.

c) Se debe garantizar a la persona acusada la posibilidad de abandonar el proceso de mediación en cualquier momento hasta el inicio del juicio oral, sin merma alguna en las garantías procesales. La normativa que regule la mediación tiene que garantizar a la persona acusada que si desea abandonar el proceso mediador iniciado, o incluso finalizado con éxito, antes del inicio del juicio oral, pueda hacerlo sin que ninguna de las expresiones efectuadas puedan ser tomadas en consideración en la vista oral. En otro sentido, deben garantizarse con absoluta plenitud todos los derechos fundamentales relacionados directamente con el proceso penal. A estos efectos se tienen que establecer las siguientes cautelas:

- Se debe garantizar la confidencialidad de la información que se vierta en el proceso de mediación para que su contenido no pueda ser utilizado en sentido incriminatorio. Esta exigencia debe quedar recogida en el do- 
cumento de consentimiento informado que se explica y entrega para su firma a las partes intervinientes y, a través del cual, surge el compromiso de la víctima, del acusado y del mediador que interviene de no relatar ni utilizar datos que se hayan conocido en las sesiones de la mediación en caso de que ésta no llegue a finalizar con éxito.

- No se puede aceptar la solicitud de prueba testifical del mediador, que queda amparado por el secreto profesional, ni de otras personas ajenas al proceso penal que estuvieran vinculadas al conflicto y que hubieran podido participar en la mediación. El mediador únicamente puede ser llamado para realizar aclaraciones sobre la disponibilidad del acusado para compensar a la víctima en el caso de que la mediación con o sin éxito, no cuente con la colaboración de esta última.

- Para reforzar el derecho a la presunción de inocencia, el juez no tendrá conocimiento del contenido del proceso de mediación, salvo los acuerdos adoptados por las partes en el documento final y que se recogen en el "acta de acuerdos", hasta el desarrollo del juicio oral, momento procesal en que las partes podrán expresar todo aquello que quieran en relación con los hechos, situación y reparación; así se evita una posible "contaminación" judicial.

- En el acta de acuerdos no se debe exigir el reconocimiento de los hechos por parte del acusado, sino únicamente el contenido de la reparación, evitando así que pueda ser utilizado en el proceso, salvo que ambas partes deseen expresamente llegar a una descripción sobre los mismos. La declaración veraz y asunción de responsabilidad del acusado se debe dejar para el acto del juicio oral, salvo que quiera lo contrario. Ahora bien, dicho esto, es obvio que el consentimiento para la participación en el proceso de mediación debe hacerse tomando en cuenta unos hechos que delimiten su desarrollo y posibiliten identificar los roles de cada uno de los intervinientes. La verdad histórica no resulta indiferente; necesariamente ha de ser reconstruida de forma consensuada y, de esta manera, poder elaborar la primera consecuencia restaurativa de carácter personal y social. Ahora bien, la fijación de los hechos base debe realizarse en condiciones de absoluta impermeabilización, de tal modo que se excluya, desde el primer momento, su traspaso o acceso directo, o colateral al proceso judicial. Ello exige que hasta el inicio del juicio sea el Ministerio Fiscal quien lleve el control de la admisión legal de la conformidad sin perjuicio de las facultades que el art. 787.2 y 3 LECr otorga al juez. De esta forma, tanto en los casos en los que alguna persona interviniente en la mediación quiere desistir de ella una vez finalizada con acuerdo antes del inicio del juicio oral, como en aquellos en que no se llegue a acuerdo, 
se garantiza que ni el juez, ni el fiscal, ni los abogados acusadores o defensores, puedan utilizar datos referidos a los hechos o expresión alguna recogida en el acta de acuerdos.

- El juez no tendrá en cuenta ningún tipo de manifestación realizada por abogados $\mathbf{u}$ otras partes procesales relativa al proceso de mediación si la persona acusada ha decidido abandonar el proceso y reconducir su situación hacia los trámites ordinarios del proceso. Dicho de otro modo, las expresiones vertidas verbal o documentalmente en el acta de reparación únicamente tendrán valor de prueba si son ratificadas como tales por la víctima y el acusado en el acto del juicio oral.

- La presencia del abogado es necesaria para garantizar el respecto a los derechos fundamentales. Esta presencia no se requiere durante el proceso de mediación propiamente dicho, pues éste es un proceso personal, privado e íntimo de diálogo en el que se vierten información, sentimientos y otros aspectos emocionales. Ahora bien, su participación es esencial en la tarea de asesoramiento sobre la posible afectación de derechos fundamentales, alcance penológico y otras consecuencias jurídicas.

\section{EL ACUERDO}

El acuerdo representa la culminación del diálogo interpersonal. Es, sin duda, una de las partes más importantes del proceso pues, con frecuencia, consolida los procesos emocionales de liberación de las posiciones inicialmente mantenidas. La persona acusada, cuando decide proponer una reparación, o aceptar la propuesta por la víctima, y viceversa, está expresando la eficacia de la empatía y la aceptación. Para la víctima, una vez expresados su temor, angustia y rabia, y tras haber escuchado la explicación del acusado con atención, actitud e intención de comprender-salir de sí-, los deseos de venganza que contienen las emociones expresadas anteriormente, suelen desvanecerse. Aparece, entonces, una sensación de paz, de calma interior, de empatía, incluso no faltan las ocasiones en que surge la compasión, ese sentimiento que nos blinda frente a la violencia. La persona acusada, una vez escuchado, atendido, explicado, comprendido, el miedo y la angustia de la persona que tiene delante, es capaz de asumir la responsabilidad personal por el daño causado. Y, en ocasiones, se desvanece el blindaje emocional o ideológico que justifica la conducta lesiva. El rostro del otro, con su enorme carga ética, permite caer en la cuenta del sufrimiento para que la posición se desvanezca. Y, con todo, el acuerdo, consolida este proceso ${ }^{18}$.

${ }^{18}$ El desarrollo de la práctica mediadora se detalla en la interesantísima tesis doctoral de Olalde Altarejos. A., Estudio multidimensional de algunas prácticas de justicia restaurativa en el País Vasco con lentes de trabajo social, Universidad de Murcia, 2015. 


\subsection{Requisitos del acuerdo}

El acuerdo debe reunir algunas características:

- Debe beneficiar a las personas que han intervenido en la mediación. Tanto la víctima, como el acusado, cuando deciden iniciar una mediación ante un conflicto delictivo lo hacen porque intuyen ciertas ventajas. Es claro que nadie emprende una acción sin que exista, a priori, un interés. En la mediación penal, la cuestión no es diferente; tanto la víctima como el agresor intuyen, en principio, la obtención de unos beneficios, aunque, con frecuencia, cuando el proceso acaba, se encuentran con el más importante: la obtención de una sensación de serenidad interna. Este beneficio ni siquiera se puede intuir al principio, aunque el mediador lo exponga en la primera entrevista, porque la posición emocional de partida no lo permite. A medida en que las partes van conociendo situaciones objetivas y subjetivas mutuas, inicialmente desconocidas y que son las que fundamentan el prejuicio crítico inicial, la comprensión de la otra parte se hace una realidad y se puede avanzar en la satisfacción de intereses concretos en forma de acuerdos. Lógicamente éstos tienen que beneficiar a las dos partes, pues si alguna de las dos no ve colmado un interés, no se sentirá vinculado por el acuerdo, la posición emocional se mantendrá y, con ella, los objetivos de la mediación quedarán frustrados. Al mediador le corresponde la tarea de hacer visibles los intereses de cada parte. No es infrecuente que para que la persona vea el interés y el beneficio de un acuerdo, no haya más que mostrar la otra cara de la moneda, es decir, el perjuicio que aparecería, de no caer en la cuenta de la ganancia. Así, en general, para el infractor, la respuesta penal íntegra, y para la víctima, la no reparación del daño sufrido en ningún nivel -material, moral, emocional- y, para ambas, en algunos casos de convivencia cercana o íntima, el mantenimiento o reproducción de futuro de la situación hostil. Por tanto, el mediador se hace responsable de que los acuerdos adoptados beneficien a las personas implicadas.

- Tiene que ser de posible ejecución. El mediador es garante de que el acuerdo adoptado se pueda cumplir. Esta cuestión es de vital importancia, pues si la persona acusada no quiere o puede realizar la obligación pactada, los objetivos positivos del proceso se desvanecerán, no sólo en un nivel legal, sino también material, ante la frustración de las expectativas puestas por los intervinientes. Por ello se necesita la constatación del mediador de que ese acuerdo es de posible ejecución a través de la información que haya ido obteniendo a lo largo del proceso mediador. Por ejemplo, no sería posible un acuerdo de reparación económica de una persona insolvente que intenta salir de la mediación expresando su deseo de pagar, o quien decida hacer una 
determinada prestación material como pintar una casa o un contenedor, si no tienen voluntad de hacerlo o desconoce la forma de llevarlo a cabo. Las consecuencias que se derivan de esta situación son mucho más perjudiciales que el abandono del proceso de mediación antes del acuerdo.

- Debe respetar siempre la dignidad de la persona que va a ejecutarlo. Para ello hay que valorar objetivamente el contenido de la prestación pactada y su repercusión subjetiva en la persona encargada de llevarla a cabo. Nuevamente, el mediador es el encargado de velar para que esto sea así. En todo caso, el abogado, en la tarea de asesoramiento legal del acusado, podrá garantizar el cumplimiento de este requisito antes de la firma del acuerdo. El fiscal y el juez, en último extremo, también lo garantizarán.

- Debe ser proporcional. Aunque la mediación concluye con manifestaciones de la voluntad de las partes concretas y libres, los acuerdos deben tener necesariamente una correlación entre la naturaleza, gravedad y repercusiones lesivas de la infracción cometida, y el tipo de obligación pactada. De esta ponderación inicial se encarga el mediador para velar por que el pacto no contenga obligaciones desproporcionadas. Esta situación podrá ser corregida por el abogado defensor quien, sin estar presente en la mediación, podrá asesorar al acusado antes de la firma de acuerdo. El fiscal y el juez, en último extremo, podrán garantizar la existencia de proporcionalidad.

\subsection{Formas de reparación}

Los acuerdos a los que se llega en mediación pueden ser de dos tipos ${ }^{19}$. De índole material, denominándose a éste, acuerdo de reparación material; o de índole simbólica, denominándose acuerdo de reparación simbólica ${ }^{20}$. Los acuerdos de contenido material consisten en la asunción de una obligación de dar una

\footnotetext{
${ }^{19}$ Según el informe de Sáez Rodriguez, cit., en Cataluña, de los asuntos cerrados con acuerdo, los de contenido económico representan poco más del 10\%; los de tipo personal y relacional supusieron un $73 \%$ en 2008 y un 86\% en 2009. En País Vasco, los acuerdos con contenido económico suponen un 9\%, ambos años. Del resto de los contenidos destacan las disculpas formales (36\%, en 2008; 23\%, en 2009); la renuncia de acciones civiles (alrededor de un 20\%); y el compromiso de no reincidir (un 10\%). En el informe del CGPJ, las fórmulas de reparación fueron muy variadas, aunque todas estaban dirigidas a un mismo objetivo: que las víctimas recuperaran la confianza y la tranquilidad personales; de ahí que resulte mayoritaria la petición de disculpas $(29,5 \%)$ y el abono de las indemnizaciones $(13,5 \%)$. Se reflejan también en el informe otras fórmulas reparatorias como la derivación a tratamiento terapéutico, la realización de servicios comunitarios, o el compromiso de respeto mutuo o de que los hechos no se repitan. La reparación efectiva se consiguió totalmente antes del juicio en el 79\% de los casos y parcialmente en el $12 \%$. Es decir, en el $91 \%$ de los casos la víctima obtuvo, antes del dictado de la sentencia, una reparación. La cifra es tan rotunda que no merece más comentario, especialmente si se compara con lo que acontece en el procedimiento penal convencional.

${ }^{20}$ Ver el interesantísimo trabajo de investigación: Varona, G. y otros., Evaluación del coste de la justicia restaurativa integrando indicadores cualitativos y cuantitativos. En el caso de la mediación penal aplicada a los delitos de menor gravedad, Gobierno Vasco, Álava, 2013, www.eukadi.eus
} 
cantidad económica o la devolución de la cosa sustraída. La cuantificación de esa indemnización económica es la determinada por el Ministerio Fiscal en la fase de enjuiciamiento, pues el escrito de acusación ya contiene la cantidad que debe entregar el acusado. En la fase de instrucción, debido a que todavía no existe un escrito de acusación del Ministerio Fiscal, habrá que estar a lo que determine el perito tasador en la valoración del daño. Si no coincide la tasación del perito adscrito al Juzgado con la tasación de un perito de parte, habrá que estar a lo que dispone el primero de ellos, pues este actúa bajo los principios de imparcialidad, ateniéndose a las tablas de valoraciones actualizadas. Cuando el acuerdo consista en el pago de la responsabilidad civil y la persona acusada no disponga de ingresos suficientes para efectuar esa responsabilidad en un solo pago, las partes pueden pactar que se haga a plazos, determinando las cuotas en el acuerdo, y en todo caso, procurando que se satisfaga íntegramente antes del acto de la vista.

Los acuerdos de reparación «simbólica» consisten en una obligación de hacer o no hacer, y nunca suponen la entrega material de dinero, pues según el art. 112 del Código Penal «la reparación del daño podrá consistir, además de en obligaciones de dar, en obligaciones de hacer o no hacer»; por tanto esas obligaciones pueden consistir en la redacción de una carta, en el sometimiento a un tratamiento de desintoxicación, en una visita a una prisión o en la realización de trabajos en beneficio de la comunidad, etc. En muchos casos, la reparación económica deviene imposible por la insolvencia del infractor y en otros muchos carecerá de interés para la víctima. En estos supuestos es cuando se recurre a la reparación simbólica. En ellos no se está reparando sólo el daño patrimonial que ha generado el delito, sino los efectos negativos que el delito también despliega en la esfera psicológica -reparación emocional-.

Los acuerdos simbólicos, según la experiencia del CGPJ, 2005-2008, alcanzan el 90\%, y los materiales el 10\%. Se han adoptado los siguientes: petición de disculpas; compromiso de tratarse con respeto, de no molestarse o insultarse, de dejarse en paz, de comunicarse en positivo, de no agredirse, indemnización económica, información sobre las repercusiones penales que pueden tener conductas agresivas, petición personal de perdón, redacción de cartas pidiendo disculpas, visita guiada por la prisión para conocer el destino de quien comete un delito, realización de actividades como pintar una casa de gente sin recursos, arreglar el jardín de una parroquia, someterse a terapia, devolver el dinero a plazos, compromisos de potenciar la buena convivencia entre las partes, en casos de menores, acuerdos en sentido educativo para con ellos (de los padres).

El acta de reparación es el documento en el que se recogen los acuerdos a los que han llegado las partes. En dicha acta no se tiene que expresar necesariamente el reconocimiento total o parcial de los hechos, salvo que la persona acusada disponga expresamente lo contrario, informándole de las consecuencias que de ello pudieran derivarse. Este documento debe contener los nombres y 
DNI de cada una de las partes implicadas, incluyendo al mediador, las sesiones de mediación que se han necesitado y los acuerdos. Debe ir firmada por las partes. De no alcanzarse ningún acuerdo, las partes deben ser informadas de que el asunto se ventilará conforme al modelo actual de justicia penal, procediéndose a la continuación del proceso, haciendo llegar al Juzgado o Tribunal un informe breve y conciso sobre la imposibilidad de llegar a un acuerdo, y reconduciendo por tanto, el asunto por la vía ordinaria. Dicho informe irá firmado solamente por el mediador y en ningún caso debe contener explicaciones acerca del porqué del fracaso de la mediación (en su caso), ni que parte ha impedido la realización de esa mediación, pues está obligado a guardar confidencialidad. De todas formas, la experiencia nos dice que en el $90 \%$ de los casos cuando se llega al encuentro dialogado, se consigue también llegar a un acuerdo.

\subsection{Seguimiento de los acuerdos}

El seguimiento persigue conocer el grado de cumplimiento de los acuerdos firmados, así como la capacidad de adaptación a cambios e imprevistos. Asimismo, el seguimiento ofrece la posibilidad de renegociar posibles problemas, siempre dentro de los plazos establecidos. Se efectuará dependiendo del contenido del mismo a través del Juzgado o Tribunal que haya derivado el asunto, que podrá ser el Juzgado de Instrucción, el Juzgado de lo Penal, la Audiencia Provincial o el Juzgado de Ejecuciones Penales; el seguimiento también se puede realizar por el equipo de mediación. En todo caso se debe procurar que haya un seguimiento efectivo y que se informe con claridad a la persona que debe llevarlo a cabo sobre los efectos que pueden derivarse de un incumplimiento. Si el acuerdo se tomó en la fase de instrucción, y no se cumple, no habrá un escrito de calificación provisional conjunto entre el Ministerio Fiscal y el abogado defensor solicitando una pena mínima en virtud de la concurrencia de la atenuante simple o muy cualificada de reparación del daño -rebaja de la pena en un grado-. Si se incumple el acuerdo en la fase de enjuiciamiento, entonces el juicio se celebrará por el cauce ordinario, y no se tendrá en cuenta la concurrencia de la atenuante mencionada. En fase de ejecución se podrá revocar, en su caso, la suspensión concedida.

El Juzgado competente podrá recabar del servicio de mediación los informes de seguimiento que considere oportunos, a los efectos de poder comprobar el cumplimiento de los acuerdos firmados por las partes. Se pueden realizar dos llamadas de control para asegurar la finalización del conflicto, salvo si se entiende que con una es suficiente. Si en el acuerdo han existido obligaciones de pago o de hacer, el mediador se preocupará de controlar su cumplimiento, entendiendo desde ese momento el comienzo del plazo para realizar las llamadas de control. Se puede establecer un seguimiento mensual en aquellos casos en que los acuerdos se alargan en el tiempo (acuerdos patrimoniales, derivación a tratamiento o a otros 
programas, trabajos en beneficio de la comunidad) o para aquellos casos en que las partes así lo decidan. En ambos supuestos se realizarán llamadas mensuales desde el servicio de mediación. Se valorará la realización de una llamada a todas las partes implicadas en el expediente (víctimas e imputados, coordinadores de los programas de derivación), o únicamente a las personas encargadas de los programas de derivación o tratamiento. En este segundo caso las llamadas a las partes se realizarán, al menos, de forma semestral. Una vez completado el acuerdo, la siguiente llamada de seguimiento a las partes se realizará al cabo de seis meses.

En los casos de ejecutorias o de sentencias firmes el servicio de mediación deberá coordinarse con los servicios de asistencia social o de apoyo comunitario para poder obtener la información necesaria para los seguimientos. El servicio de mediación colaborará en aquellos casos de mediación en los que se establezca suspensión de la pena condicionada al cumplimiento de algún tipo de programa (art. $83 \mathrm{CP}$ ).

\section{INCORPORACIÓN DE LA MEDIACIÓN AL PROCESO PENAL}

Son varios los cauces que ofrece el sistema para la introducción de la mediación. Si durante la fase de instrucción se llega a un acuerdo, el Ministerio Fiscal puede tenerlo en cuenta en la calificación y petición de pena de su escrito de acusación, pudiéndose llegar a la conformidad de acuerdo con lo establecido en el art. 738.4 LECrim. A través de la conformidad también es posible canalizar el acuerdo de reparación adoptado tras el auto de apertura del juicio oral (art. 787 LECrim). Asimismo, la mediación y el eventual acuerdo pueden ser tenidos en cuenta a través de la atenuante de reparación del daño (art. $21.5 \mathrm{CP}$ ) ${ }^{21}$, aplicable como atenuante simple o muy cualificada. En fase de ejecución a través de la suspensión $^{22}$, pudiéndose imponer el cumplimiento del acuerdo al que se hubiera llegado como condición a cumplir durante el periodo de suspensión ${ }^{23}$. También puede ser tenida en cuenta a los efectos de emitir informes favorables al indulto o a los efectos de la suspensión durante la tramitación del indulto (art. 4.4 CP). Habrá de valorarse asimismo las posibilidades de la mediación durante el cumplimiento de una pena de prisión y su repercusión, por ejemplo, a efectos de la progresión de

\footnotetext{
21 "Son circunstancias atenuantes: La de haber procedido el culpable a reparar el daño ocasionado a la víctima, o disminuir sus efectos, en cualquier momento del procedimiento y con anterioridad a la celebración del acto del juicio oral" (art. 21.5 CP).

${ }^{22} \mathrm{El}$ art. 84.1 CP establece que "El juez o tribunal también podrá condicionar la suspensión de la ejecución de la pena al cumplimiento de alguna o algunas de las siguientes prestaciones o medidas: 1 a $^{\mathrm{a}} \mathrm{El}$ cumplimiento del acuerdo alcanzado por las partes en virtud de mediación".

${ }^{23} \mathrm{El}$ art. $80 \mathrm{CP}$ contempla la suspensión de la pena de hasta 2 años de prisión atendiendo a distintas circunstancias "en particular, el esfuerzo por reparar el daño causado".
} 
grado, exclusión del periodo de seguridad de cinco años que prevé el art. $36.2 \mathrm{CP}$, adelantamiento y concesión de la libertad condicional en sus diversas modalidades ${ }^{24}$, etc. En fase de ejecución penal destacan por su relevancia metodológica los encuentros restaurativos entre víctimas y ex miembros de ETA ${ }^{25}$.

\section{EXPERIENCIAS NACIONALES E INTERNACIONALES}

Las experiencias internacionales en el ámbito de la mediación más relevantes se inician en EEUU y en Canadá en los años 70, partiendo del cuestionamiento de la legalidad penal de los movimientos abolicionistas y de la creciente importancia de la víctima y de la reparación. En 1974 se inició un proyecto de conciliación víctima-ofensor (VORP) en Ontario, Canadá, en el ámbito del Derecho penal juvenil En 1977, se inician en Gran Bretaña varios programas de mediación para jóvenes y adultos destinados a la resolución de disputas entre vecinos. El objetivo de estas experiencias, conocidas como neighborhood justice era evitar los efectos negativos de una judicialización excesiva. En torno a 1985, la mediación se inicia en Holanda, Alemania y Austria. En Francia, los primeros programas se iniciaron en los años 80 y se pusieron en marcha gracias a las Fiscalías de Valence y Grenoble, con la participación de las oficinas de atención a las víctimas. El Instituto Nacional de Ayuda a las Víctimas de Mediación agrupa la mayor parte de las asociaciones de asistencia a la víctima y fomenta el desarrollo de la mediación. La experiencia más importante es la que realiza le Boutique de Droit a partir de la Ley de 1993. En Bélgica la mediación se inicia a partir de la promulgación de la Ley de 10 de febrero de 1994, aunque las primeras experiencias comenzaron en 1992. En Alemania, las primeras experiencias tuvieron su inicio bajo la denominación de Programas de conciliación víctima-autor (Täter-Opfer-ausgleich), de características similares a los Victim Ofender Reconciliation Programs. En 1992 se creó un servicio especial de asesoramiento, financiado por el Ministerio de Justicia. Así mismo, siguiendo a Varona ${ }^{26}$, hay que mencionar al menos tres experiencias anglosajonas de referencia: la de Gavrielides, la de Shapland y la de Sheman y Strang.

Las experiencias nacionales han sido varias. En Valencia, el Juzgado de Instrucción núm. 2 de esta capital, por medio de un convenio con la Oficina de Atención a la Víctima, comenzó en 1993 un programa de mediación con adultos

\footnotetext{
${ }^{24} \mathrm{El}$ art. 90.2 CP: contempla la participación en programas de reparación del daño (con beneficios de reducción del período de libertad condicional para el penado).

${ }^{25}$ Pascual Rodríguez, E., y otros, Los ojos del otro: encuentros restaurativos entre víctimas y ex miembros de ETA, Salterrae, Bilbao, 2013.

${ }^{26}$ Varona, G., Justicia restaurativa a través de los servicios de mediación penal en Euskadi. Evaluación externa de su actividad (Octubre 2008-Septiembre 2009), Consejería de Justicia del Gobierno Vasco, 2009.
} 
para delitos y faltas. El 20\% de los casos tuvieron éxito, frente al 20\% restante que fueron negativos y el resto o lo solucionaron solos o quedó en suspenso. En Cataluña comenzaron los primeros programas de conciliación y reparación en el ámbito de la delincuencia juvenil en 1990. En 1998, la Dirección General de Medidas Penales Alternativas y Justicia Juvenil inició un proyecto de mediación y reparación de adultos como experiencia piloto. En junio de 2002 se hizo un primer análisis para valorar los cuatro primeros años de implantación, según el cual de 452 asuntos iniciados, 116 no se consideraron viables y de 210 asuntos en los que constaba el resultado, el 66\% llegó a un acuerdo de mediación· En Madrid, la asociación «Apoyo» comenzó un programa de mediación comunitaria víctima e infractor. A diferencia de las anteriores, la mediación se hace en el seno del tejido asociativo y comunitario. En 2001 fueron atendidas 160 personas, de las que 119 eran infractores drogodependientes y 41 víctimas. La experiencia continúa y está obteniendo importantes resultados positivos. Actualmente existen múltiples experiencias en diferentes órganos jurisdiccionales amparadas por el Consejo General del Poder Judicial. Cabe afirmar sin dudas, señala Sáez Rodríguez $z^{27}$, que la mediación penal practicada con arreglo a los protocolos y documentos de intervención elaborados ha generado unos resultados que cualitativa y cuantitativamente superan las más optimistas expectativas. Incluso en aquellos casos en

\footnotetext{
${ }^{27}$ Sáez, C., "Mediación penal. Informe de evaluación y situación”, Investigación promovida por el Consejo General del Poder Judicial, 2009/2010. En este excelente análisis se recogen los datos cuantitativos de viabilidad de las experiencias realizadas en España:

A nivel nacional, el $37 \%$ de los asuntos que se derivan no resultan viables. Llama la atención que de ellos, casi el $80 \%$ se deba a diversas incidencias relacionadas con la víctima (por no localizarla; por su incomparecencia o porque no lo desea).

En Cataluña, la tendencia es al descenso, de un $58 \%$ a un $46 \%$, en los porcentajes de viabilidad de 2008 a 2009. Del número de asuntos inviables, el 38\% se atribuyó a incidentes relacionados con la víctima y el 18\%, al imputado (porcentaje éste que ascendió en 2009 al 25\%).

En Euskadi, en 2008, los asuntos que se cerraron sin realizar mediación representaron el 33\%, y en 2009 no llegó al 30\%. Los motivos imputables a la víctima (por no ser localizada o no desear iniciar el proceso) son siempre inferiores porcentualmente a los que se refieren al imputado: en ambos años se cifran en el 39 y el $51 \%$, respectivamente.

En el informe sobre los programas-piloto, de los asuntos derivados a mediación no pudieron ser iniciados el 40\%. Entre las causas destacaron la imposibilidad de localizar a la víctima (9\%) o al infractor (22\%), o no desearlo la víctima (33\%) o el infractor $(28 \%)$.

Tanto en el documento del CGPJ respecto del primer semestre de 2009, como en la Memoria de Cataluña respecto de 2008 y 2009, el porcentaje de los asuntos cerrados con acuerdo ronda el $80 \%$; en el caso de Euskadi, superó en ambos años el 83\%.

En el informe de los programas-piloto, de las mediaciones que pudieron iniciarse, el porcentaje de acuerdos llegó al $71 \%$, alcanzándose el mayor número de ellos en las causas por delito (50\%); las faltas representaron el $43 \%$.

Un dato que sólo se ha recogido en Euskadi, en la Memoria de 2009, que estimamos de interés reseñar hace referencia a los motivos que impidieron el acuerdo en las mediaciones iniciadas. Los más relevantes porcentualmente son: el desacuerdo en la prestación económica (19\%); en la versión de los hechos $(15 \%)$; por la cronificación del conflicto $(13 \%)$ y por no moverse las partes de sus posiciones iniciales $(11 \%)$.
} 
que no se logra alcanzar todos los objetivos propuestos, se manifiesta positiva, desde la perspectiva de las víctimas, para satisfacer sus legítimos intereses y dar cobertura a sus necesidades y desde el punto de vista del infractor, al implicar un plus en su grado de responsabilización, tanto en términos jurídicos, reconociendo y reparando el perjuicio material causado, como éticos porque la asunción del perjuicio causado permite en muchos casos la reconducción de su propia vida por sendas de normalización conductual y de respeto al ordenamiento jurídico. Resulta igualmente destacable que muchas mediaciones terminadas con éxito no sólo se ciñen al concreto ámbito en que se desarrollan, de manera que en más del $70 \%$ de ellas el conflicto no solo logra ser superado y las heridas derivadas del mismo desaparecen, sino que despliega su eficacia positiva incluso en otros procedimientos judiciales que se tramitan entre las mismas personas en conflicto. De ahí otra de las virtualidades no siempre reconocidas a la mediación: conseguir, en la medida en que los implicados así lo deseen, profundizar en otros conflictos y actuar de tal manera a nivel preventivo, mirando al futuro.

\section{CONCLUSIONES}

Primera. La mediación aplicada al derecho penal de adultos no constituye una alternativa al proceso penal sino una metodología que, sustentada en los basamentos ideológicos de la justicia restaurativa, se engarza en el procedimiento actuando desde y para el sistema reglado de justicia penal, y contribuye a la consecución de sus fines.

Segunda. La mediación penal no sólo no repercute negativamente sobre los derechos y garantías sustantivas y procesales de las partes sino que los refuerza; su impacto jurídico les resulta beneficioso a ambas. A estos efectos hay que tener todas las prevenciones señaladas en el apartado tercero de este artículo.

Tercera. Los efectos positivos generales de la mediación penal apuntan a la mejora del servicio público de justicia penal, al incremento de la cohesión social, a la reintegración social del infractor y la mejor protección de los intereses de la víctima, al positivo efecto en el manejo pacífico de los conflictos, que mira al futuro y previene conflictos por venir. También se estima más eficaz que la justicia penal convencional como mecanismo de control social. Sin embargo se deben también mencionar sus riesgos: por un lado los peligros de una posible banalización del modelo y el deterioro de las garantías procesales.

Cuarta. La justicia restaurativa parte de la víctima y de sus intereses, pero los hace confluir con los del infractor y con los de la comunidad; la paz y el diálogo social que el delito quebró serán así restablecidos y saldrá fortalecida la vigencia de la norma. La justicia restaurativa apela, pues, "a lo mejor" de cada ser humano, también del infractor, al que invita a reconocer la verdad, a hacerse responsable 
de sus consecuencias, a abandonar un estilo de vida poco respetuoso con el prójimo (aunque sea consecuencia de una historia de desatención y carencias) y a alcanzar autonomía y respeto a las normas de convivencia social. En términos de invitación, no de imposición.

\section{BIBLIOGRAFIA}

BRAITHWAITE, J., "The fundamentals of restorative" en Dinen, S., Jowit, A. y Newton, T. (eds.), A Kind of Mending: Restorative Justice in the Pacific Islands, Australian National University Press, Camberra, 2010, pp. 35-43.

CHRISTIE, N., Los límites del dolor, Fondo de Cultura Económica, México, 1984.

JONAS, H., El principio de responsabilidad, Herder, Barcelona, 1995.

MARTINEZ ESCAMILLA, M., "Justicia reparadora, mediación y sistema penal. Diferentes estrategias, ¿los mismos objetivos?", en Estudios Penales en Homenaje a Enrique Gimbernat, Edisofer, Madrid, 2008.

NICOLAS MARÍN, J. A., "La teoría zubiriana de la verdad", en Nicolás Marín, J. A. y Barroso Fernández, O. (cols.), Balance y perspectivas de la filosofía de X. Zubiri, Comares, Granada, 2004, pp. 129-147.

OLIVA SANTOS, A, "Presunción de inocencia, prueba de cargo y sentencia de conformidad", http://www.ucem.es/info/procesal/revista/inocencia. html.

OLALDE ALTAREJOS. A., Estudio multidimensional de algunas prácticas de justicia restaurativa en el país vasco con lentes de trabajo social, Tesis doctoral, Universidad de Murcia, 2015.

PASCUAL RODRIGUEZ, E., "La mediación en el Derecho penal de adultos en la fase de enjuiciamiento", Estudios de Derecho Judicial, (núm. 111, 2006), pp. 107-138.

PASCUAL RODRIGUEZ, E., y otros, Los ojos del otro: encuentros restaurativos entre víctimas y ex miembros de ETA, Salterrae, Bilbao, 2013.

PRANIS, K., "Restorative values" en Johnstone, F. y Van Ness, D. W. (eds.), Handbook of restorative justice, Willan Publishing, Nueva York, 2007, pp. 59-74.

ROJAS MARCOS, L., “¿Condenados a víctimas perpetuas?”, El País, (28 de julio de 2005).

ROXIN, C., "La reparación en el sistema de los fines de la pena", en Maier, B. J. (comp.) De los delitos y de las víctimas, Ad-hoc, Buenos Aires, 1992.

SAEZ, C., La Mediación Penal y Penitenciaria. Un programa para su regulación, Thompson-Aranzadi, Pamplona, 2008. 
SAEZ, C., "Mediación penal. Informe de evaluación y situación”, Investigación promovida por el Consejo General del Poder Judicial, 2009/2010.

SÁNCHEZ ALVÁREZ, P., "Mediación penal comunitaria: desde dónde y hacia dónde", Estudios de Derecho Judicial, (núm. 11, 2006), pp. 23-34.

SILVA SÁNCHEZ, J., "Sobre la relevancia jurídico-penal de la realización de actos de "reparación”", Revista del Poder Judicial, (núm. 45, 1997), pp. 183-202.

UNITED NATIONS, Handbook on restorative justice programmes, Criminal Justice Handbook Series New York: United Nations - Office on Drugs and Crime, New York, 2006.

VARONA, G., Justicia restaurativa a través de los servicios de mediación penal en Euskadi. Evaluación externa de su actividad (Octubre 2008-Septiembre 2009), Consejería de Justicia del Gobierno Vasco, 2009.

VARONA, G. y otros, Evaluación del coste de la justicia restaurativa integrando indicadores cualitativos y cuantitativos. En el caso de la mediación penal aplicada a los delitos de menor gravedad, Gobierno Vasco, Álava, 2013, www.eukadi.eus 